\title{
La producción del espacio. Reflexiones en torno a los procesos de relocalización de población. Mar del Plata, 1998-2013*
}

The Production of Space. Reflections about Relocation of Population. Mar del Plata, 1998-2013

A produção do espaço. Reflexões em torno a processos de velocalização de população. Mar del Plata, 1998-2013

\section{Ana Núñez **}

Recibido: 17 de abril de 2015

Aprobado: 13 de agosto de 2015

Doi: dx.doi.org/10.12804/territ34.2016.05

\section{Para citar este artículo}

Núñez, A. (2016). La producción del espacio. Reflexiones en torno a los procesos de relocalización de población. Mar del Plata, 1998-2013. Territorios, 34, 113-135. Doi: dx.doi.org/10.12804/territ34.2016.05

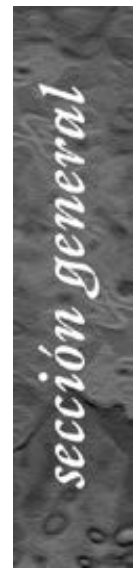

* Este artículo deriva del proyecto de investigación pict 2013-2053, denominado "Prácticas espaciales desobedientes, de posesión y resistencia. Análisis comparativo de procesos de apropiación/expropiación de la territorialidad social en ciudades argentinas", (continuación del proyecto ya finalizado pict 20102414), evaluado y financiado por el Fondo Nacional de Ciencia y Tecnologia, de la Agencia Nacional de Promoción Científica (FONCYT/ANPCYT), $y$ del proyecto evaluado y financiado por la UNMdP, denominado "Producción del espacio. Apropiación yexpropiación de territorialidades sociales en ciudades argentinas, última década”, todos bajo la dirección de la Dra. Ana Núñez. Agradezco profun- $\Rightarrow$ 
Palabras clave

Burocracia, Personificaciones, Producción del espacio-tiempo, Programas de viviendas.

Keywords

Bureaucracy, Personifications., Space-time production, Housing programs.

Palavras-chave

Burocracia, Personificações, Produção do espaço-tempo, Programas de Habitações.

\section{tersitarias 34}

\section{RESUMEN}

Desde comienzos de la década del 2000 se promovieron, en una ciudad media argentina, varios programas de construcción de viviendas sociales con el fin de atender distintas situaciones de la problemática habitacional. Dos de dichos programas (Plan Federal y Programa Dignidad) desataron la llamada guerra por las casas entre los potenciales beneficiarios debido, en parte, a los varios años que transcurren entre censos, registros y clasificaciones que determinan quién, cómo, cuándo y dónde será adjudicatario de tan preciado objeto. El objetivo de este texto es analizar dialécticamente la relación entre los programas, el proceso de relocalización de la población y la burocracia, con el propósito de develar los obstáculos epistemológicos que reproducen el problema que se pretende atacar. Para ello, esta investigación se centrará, acompañada de las sugerencias de Henri Lefebvre, en la interrelación y transformación de los tres momentos que se imbrican dialécticamente en la producción del espacio, y cómo permea el conjunto de interdependencias sociales en la vida cotidiana, transfigurando las personificaciones, según el sentido que cada quien le da al suelo y a la vivienda. El proceso de conocimiento de esta investigación se ancla metodológicamente en un extenso y profundo trabajo de campo y análisis documental, en la ciudad de Mar del Plata como unidad de estudio.

\section{ABSTRACT}

Since the early 2000s, many housing programs were promoted in a medium-sized city in Argentina. Two of these programs (Plan Federal y Programa Dignidad) led to what is known as 'war for houses' between the potential beneficiaries, because of the years of censuses, records, and rankings which determine who, when and where would be awarded with such a precious object. The aim of this text is to dialectically analyze the connection between the programs and the relocation process of the population and bureaucracy in order to uncover the epistemological obstacles that aggravate the problem in question. Accompanied by ideas of Henri Lefebvre, this research will focus on the interrelation and transformation of three moments that overlap dialectically in the space production, and how it permeates the social interdependencies in everyday life, transfiguring the personifications according to the sense that everyone gives to the soil and housing. This research's process of knowledge is methodologically anchored in an extensive, deep fieldwork and documentary analysis taking the city of Mar del Plata as unit of study.

\section{RESUMO}

Desde começos da década do ano 2000 promoveram-se em uma cidade média argentina, vários programas de construção de habitações sociais com o fim de atender distintas situações da problemática habitacional. Dois de ditos programas (Plan Federal e Programa Dignidad) desataram a chamada "guerra pelas casas" entre os potenciais beneficiários devido, em parte, aos vários anos que transcorrem entre censos, registros, e classificações que determinam quem, como, quando e onde será adjudicatório de tão prezado objeto. O objetivo deste texto é analisar dialeticamente a relação entre os programas, o processo de relocalização da população e a burocracia, com o propósito de revelar os obstáculos epistemológicos que reproduzem o "problema" que se pretende atacar. Centramonos, acompanhados das sugestões de Henri Lefebvre, na inter-relação e transformação dos três 
momentos que se imbricam dialeticamente na produção do espaço, e como permeia o conjunto de interdependências sociais na vida cotidiana, transfigurando as personificações, segundo o sentido que cada quem lhe dá ao solo e a habitação. Nosso processo de conhecimento fixa-se metodologicamente em um contexto y profundo trabalho de campo e análises documental, na cidade de Mar de Plata como unidade de estudo.

\section{Introducción}

Desde hace varios años, se emprendió el análisis de políticas públicas, en general, y urbanas, en particular, desde una perspectiva distinta a aquellos que parten del Estado considerándolo como algo dado, cosificado o reificado (Núñez, 2009, 2010, 2012a). En estos estudios, se le intenta devolver la dinámica en su relación conflictiva (confrontación) que establece con las fuerzas sociales (Marx, 1968; Marx \& Engels, 1968), lo que permite pensar la estatalidad ${ }^{1}$ como una posible operacionalización para analizar las interconexiones en las prácticas cotidianas, naturalizadas en apariencias fetichizadas. En otras palabras, pareciera más fructífero, empíricamente, y más fértil, teóricamente, analizar los mecanismos que dispersan, diluyen y fragmentan la lucha de clases. Precisamente, las formas en que se organizan los intereses sociales y económicos particulares, desde la dominación capitalista, pueden ser mejor comprendidas a través de Marx (1968), cuando esclarece las relaciones entre burocracia y corporación:

Las corporaciones son el materialismo de la burocracia [...] La burocracia es el círculo del que nadie puede escaparse [...]. Pero en el propio seno de la burocracia, el espi- ritualismo se hace un materialismo sórdido, se transforma en el materialismo de la obediencia pasiva.

En este andamiaje conceptual, no podríamos concebir la política urbana como un producto de actores sociales, sino como una forma, proceso e instrumento de lucha social (Núñez, 2011a, 2012a).

En este mismo sentido, también se deben sortear los obstáculos epistemológicos que interponen pensar la ciudad como contexto, cristalizando su origen y expansión en un mundo fetichizado, y por ello se ancla empíricamente su génesis como un momento de la lucha de clases (Núñez, 2008, 2012b).

En efecto, tal como se ha planteado en trabajos anteriores, en el marco de un conflicto interburgués, entre 'costeros' y 'serranos', en plena edad de oro del régimen oligárquico en la Argentina, el pueblo Mar del Plata emerge como un loteo privado aprobado por excepción en 1874. Un intercambio de favores, transgrediendo la ley de ejidos por parte de la misma estatalidad. En otros términos, una ilegalidad fundante y arbitrariedad que instauran las condiciones jurídicas de existencia del suelo urbano como mercancía (Núñez, 2008, 2011a, 2012b). damente los comentarios del evaluador anónimo, especialmente aquellos que han posibilitado enriquecer el texto.

** Arquitecta, Universidad Nacional de Mar del Plata. Magister y Doctora en Ciencias Sociales por Facultad Latinoamericana de Ciencias Sociales (FLACSO). Especialista en Politicas y Mercados de Suelo en América Latina, Universidad Nacional de Colombia. Profesora Titular Regular de Urbanismo. Investigadora Categoría I del SIN. Directora del Grupo de Investigación en Socio-Antropologia Urbana, Universidad Nacional de Mar del Plata (Argentina). Correo electrónico:aenunez@mdp. edu.ar

${ }^{1}$ Por estatalidad profunda se entienden las estrategias de reproducción adaptativas; trayectorias, vínculos $y$ relaciones sociales en el entramado de instituciones politicas; entre el secreto $y$ la lucha por abrirse camino (Marx, 1968); y por estatalidad extensa la permeabilidad hacia y con el exterior (burocracia-pecinos-empresas), a la construcción y reproducción de estrategias y categorias que reproducen el orden dominante en las instituciones sociales. Se trata de ver cómo ambas se vertebren y se mantienen $\Rightarrow$

territarios 34 
en una vaporosa indefinición, en cuanto a limites y contenidos, $y$ así se instala en el imaginario (Lourau, 1980). Ver Núñez (2009, 2012).

\section{territarias 34}

A partir de esta génesis, se conjugan dos procesos fundamentales. Por un lado, la tierra pasa de ser un fin, a ser un medio. Se transforma el uso del suelo de rural a urbano, como fuente de renta. Por otro, la incipiente mirada al mar como un nuevo instrumento que transformaría el rol del pueblo en la división nacional del trabajo signará el predominio histórico de la lógica del capital comercial, y la reproducción del excedente en los servicios, lo que favorece, a su vez, la especulación inmobiliaria (Núñez, 2012a). Todo ello va a ser acompañado de la progresiva diversificación y estacionalidad del mercado de trabajo local, lo que repercute en la recepción de fuertes contingentes migratorios de población en edad activa, de ultramar primero, y de otras provincias argentinas, posteriormente.

La normatización del mercado de suelo urbano, en la articulación del capital comercial y el capital inmobiliario, significó un instrumento de violencia legítima y simbólica en tanto dependió de unos pocos terratenientes qué, cómo, cuánto, dónde y para quién lotear, creando la periferización. En otras palabras, inventando barrios en suelos rocosos, bajos, inundables, inexplotados por el capital, para espacializar y ordenar esa fuerza social de oposición, extranjerizante, dispersa, de manera de ejercer el derecho de exclusión de este espacio urbano que se representaba hegemónicamente como objeto privado de una fracción de la burguesía nacional pero que, a la vez, era concebido como fuente de renta. El desenvolvimiento de la urbanización fue el ejercicio de ese monopolio, operando sucesivos desplazamientos de aquella periferización.

En otras palabras, hubo un proceso de concentración y retención de la propiedad privada del suelo, su encarecimiento progresivo e incremento de la renta diferencial por distintas inversiones e intervenciones urbanas lo que coadyuvó a la expulsión de los sectores populares hacia zonas urbanas carentes de los más elementales servicios, sin equipamiento, con riesgo de inundabilidad, etc.

Tal como se demuestra en Núñez (2013a), en los últimos periodos intercensales, Mar del Plata desacelera su ritmo de crecimiento poblacional, se mantiene sin variaciones el hacinamiento personal $(22,5 \%)$, la tenencia insegura del suelo $(17 \%)$ y el $10 \%$ de viviendas precarias, mientras aumenta la construcción de viviendas, pero permanece un $30 \%$ o $35 \%$ del parque desocupado en zonas accesibles y bien servidas. Esta contradicción entre necesidades y viviendas vacantes se da en un contexto de ausencia de políticas públicas integrales y preventivas del problema habitacional, acompañadas con una serie de mecanismos y procesos diversos que promuevan y garanticen la integración socioespacial.

En efecto, siguiendo a Núñez (2004), hacia fines de 2002 , el $45 \%$ de la población de Mar del Plata se encontraba debajo de la línea de pobreza; el $20 \%$ bajo la línea de indigencia; y la tasa de crecimiento anual de la población que habitaba en espacios de extrema pobreza, entre 1991 y 2001 , casi sextuplicaba la tasa de crecimiento anual de la población total. 
Asimismo, según datos del Instituto Nacional de Estadísticas y Censos, en el primer trimestre de 2002 el índice de la actividad de la construcción (ISAC) en la Argentina cae un $41,8 \%$, respecto del mismo trimestre del año anterior, y un 21,8\% respecto del trimestre anterior; y los puestos de trabajo con aportes, un $46,5 \%$ y un $14,5 \%$, respectivamente.

En este contexto, a comienzos del año 2003, se implementaron en la ciudad distintos programas habitacionales, como forma de contención social y reactivación económica. Por un lado, el registro de demanda ${ }^{2}$ habitacional que se abrió para posibles beneficiarios de alguna de las 2018 viviendas $^{3}$ que se construirían dentro del Plan Federal y, por otro, el Subprograma Bonaerense IX-Dignidad, destinado a "eliminar las viviendas insalubres y el hacinamiento", (Instituto Provincial de la Vivienda, 2003) bajo la modalidad de un Convenio entre el Instituto Provincial de la Vivienda, la Municipalidad de Gral. Pueyrredon y una asociación intermedia, la ONG Trabajar, presidida por líderes de la Unión Obreros de la Construcción de la República Argentina (UOCRA) local.

En la ciudad de Mar del Plata, este último Programa IX-Dignidad derivó en la construcción de 500 viviendas $^{4}$, que serían destinadas al proyecto, surgido en 1998, aún inconcluso, de erradicación de la población de Villa Paso, una de cuyas particularidades refiere a que ya había sido erradicada, también, en 1970 (Núñez, 2011b). En síntesis, se proyectaban 2518 viviendas, para un congelado y supuesto déficit de 11000 familias en emergencia, y 500 de un asentamiento.

En la implementación de estos programas públicos habitacionales, cuya paradójica localización es en territorios de aquella periferización de 1910, el proceso de registro, selección y adjudicación de viviendas es complejo y está signado por tensiones y conflictos entre todos los sujetos involucrados (Núñez, 2010).

Sin embargo, hay que preguntarse ¿qué significados adquiere la vivienda en la configuración de relaciones sociales?, ¿qué relaciones sociales se ocultan detrás de la materialidad de los objetos? (Marx, 1965), ¿cómo trasmuta la vida de los implicados, habitantes y burócratas en torno a un bien que escasea? ya que estos programas de construcción de viviendas que se mencionaron desataron lo que se conoce como "la guerra por las casas":

Lo que sucede es que esta demora, el tema de la usurpación última, desató la guerra por las casas. Pero ¡la guerra! El otro día vinieron dos y me dijeron 'G., le van a sobrar casas'. '¿Cómo que van a sobrar casas' 'Sí, porque se están matando'. Literalmente ¿eh? (Comunicación personal con G. C., Directora de Promoción Social, MGP, 2009).

Sin embargo, para no quedar entrampados en falsas dicotomías, se hablará de la explosión del espacio (Lefebvre, 1976, p. 130), en tanto interesa contraponer la dinámica socio-temporal y territorial de
${ }^{2}$ Para un análisis del tránsito entre carencia material y la construcción normativa de lo que debe demandarse, ver Núñez (2007).

${ }^{3}$ Es notable el desconocimiento que existe en la ciudad sobre la problemática habitacional. Desde el ámbito politico-burocrático se ha difundido información en la prensa, con pocos dias de diferencia, de 7000, 11000 y 20000 familias en situación de emergencia babitacional, además de ignorar cómo se compone en términos cualitativos. Ver un análisis de este tema en Núñez (2010, 2013).

${ }^{4}$ Distribuidas en tres barrios diferentes de la ciudad, El Martillo, Don Emilio y Las Heras, con características sociales y urbanisticas completamente disimiles entre ellos.

territarios 34

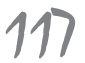


los sectores populares a la cosificación y homogeneidad racionalizadora del espacio-tiempo concebido por la estatalidad. Durante años, suceden censos y registros, clasificaciones y especificidades sociales, diría Antonadia Borges (2003), que determinarán quién, cuándo y dónde será adjudicatario de tan preciado objeto: una casa, pero en otro lugar, distinto al que habita ahora. Como si el ritmo de la vida de las familias pudiera detenerse por el solo hecho de guardar un papel donde consta "ya censado". Empero, no hay relación lineal ni mero clientelismo. El espacio-tiempo concebido (Lefebvre, 1976) se entrelaza, transformándose mutuamente, al espacio vivido y al percibido. Esa transformación tiene que ver, también, con el sentido que cada quien le da al suelo y a la vivienda, y cómo ello permea las distintas formas de involucramiento de y con la burocracia, que se sostiene omnipotente e infinita sobre la propiedad privada (Marx, 1998); y con el conjunto de interdependencias sociales en su vida cotidiana.

Por eso, no se habla de una política de vivienda, sino de cómo la política se construye, no sin tensiones, por, en y con las viviendas, entre habitantes y burocracia, con el propósito de develar algunos aspectos de la problemática habitacional que operan como obstáculos epistemológicos $y$, por ende, reproducen el problema que se pretende resolver.

Pero, “¡cómo dar cuenta del presente de un lugar en el que las vidas de las personas, expresadas sobre todo en los objetos que las circundan, están en constante cambio?" (Borges, 2003, p. 15). Esto se realiza con las sugerencias de Lefebvre (1976, 2013) sobre los tres momentos que se imbrican dialécticamente en la producción del espacio, que son el espacio percibido (las prácticas espaciales, cómo se genera, se usa y se percibe el espacio); el espacio concebido (las representaciones del espacio derivadas de saberes técnicos y racionales, vinculados con las instituciones del poder dominante); y el espacio vivido o de resistencias, en el que los actores se niegan a aceptar el poder hegemónico, pero también sufren las consecuencias del espacio.

Relacionar tiempo y espacio reconoce, en el método lefebvriano, una doble complejidad, horizontal y vertical; un desdoblamiento metodológico regresivo-progresivo, que permite identificar y recuperar esas temporalidades desencontradas, pero coexistentes. En el devenir lefebvriano, el regreso al pasado podría dar lugar al cambio, ya que la producción del espacio requiere de una ciencia del espacio-tiempo (Lefebvre, 1976), no separando lo posible de lo real, apreciando lo real en función de lo posible, y recíprocamente.

Pero, ¿cómo se entrelaza esa tríada dialéctica con las diversas temporalidades?, ¡cómo se organizan las creencias y se captan y tetanizan por la burocracia, volviendo la alienación teórica, práctica? (Lefebvre, 1971).

Para poder comprender todos estos procesos, como así también por qué este proyecto de relocalización continúa 
inconcluso ${ }^{5}$, se camina sobre los escombros y basurales que dejaron deliberadamente las topadoras que demolieron las casas de quienes ya fueron (des)localizados; se ve cómo, sobre ellos, están siendo reconstruidas por otras familias que llegan a $\mathrm{La}$ Loma; se conversó largamente con quien se resiste a irse y con quienes ya no aguantan la espera; con quienes van y vienen; con los funcionarios que deciden; con quienes reconstruyen su vida (re) y (des)localizados... En otros términos, esta investigación se ancla empíricamente en el trabajo de campo etnográfico (Guber, 2013), realizado en los distintos espacios sociales que se transitaron junto con todos los pobladores, tanto en Villa Paso, como en los distintos barrios de destino, intentando hacer emerger esa doble complejidad del método lefebvriano ${ }^{6}$. Por ende, el trabajo de campo se articuló a partir de relevamientos y observación in situ, entrevistas en profundidad a distintos miembros de las tres generaciones de familias afectadas por estas dinámicas, a población originalmente residente en los barrios de destino, como así también a funcionarios locales clave en el proyecto e implementación de esta política de relocalización.

\section{Los inicios}

Territorialmente, La Loma es el lugar donde hace más de setenta años constituyeron progresivamente su habitar familias argentinas, tanto nativas de la ciudad como migrantes. Un habitar que el orden hegemónico no tardó en denominar Villa de Emergencia ${ }^{7}$. Abriendo un paréntesis, qui- siéramos decir que coincidimos con Borges (2003) en que:

[...] Lo que en algún momento nos puede haber parecido un paso adelante por tratarse de la construcción de conceptos para aprehender cierta realidad, con el tiempo pasó a hacer parte de esa propia realidad y, por lo tanto, debe ser cuestionado y reformulado y no aceptado como inmutable.

Así aconteció con el esfuerzo de cientistas sociales, particularmente en la Argentina, en torno a 'depurar' y definir las características de villas y asentamientos, englobados como asentamientos precarios e informales (Clichevsky, 2003). Es decir, a veces, no somos del todo conscientes de que al encorsetar conceptualmente una cierta realidad, con el tiempo pasa a cosificarse (Borges, 2003), reproduciendo y profundizando la sociodinámica de la estigmatización (Elías, 2003).

De permanecer aferrados a esa conceptualización, no se podría explicar cómo está organizado el proceso de apropiación del espacio por cuatro generaciones, que en la villa, de seis manzanas perfectamente regulares, se inicia con la decisión - por parte del propietario legal de la tierra- de pagar mensual y puntualmente, durante más de cincuenta años, a una familia cuidadora; que esta, a su vez, seleccione y dé permiso a otra; que, una vez así instalados, llamen a más familiares; que la ocupación del lote sea según el recorrido del sol; carpinteros y constructores que edificaban habitaciones y casillas para alquilar o vender; que
5 Tal como se desarrollará más adelante, el proyecto de relocalización data de 1998, pero el traslado de algunas familias se inicia recién en el año 2006 y, según la hipótesis que emana de este trabajo, la concreción definitiva pareciera ser una ilusión estatal.

${ }^{6}$ Los instrumentos del trabajo de campo se elaboraron colectivamente entre los equipos de investigación de Córdoba, Santa Fe y Mar del Plata, ciudades que abarca el proyecto mayor, y en las que la producción de información primaria se realizó simultáneamente entre 2011 y 2013, para luego realizar el procesamiento comparativo de los procesos. Sin embargo, las investigaciones con las distintas generaciones que habitaron y habitan Villa Paso datan desde fines de la década de 1980 basta la actualidad, por lo cual, en más de una oportunidad, se apelará en el texto al conocimiento acumulado al respecto, dejando constancia que los nombrese iniciales son ficticios. Ver Núñez (2001a y 2011c). Es decir, la proximidad residencial $y$ los vínculos que se tejieron con las familias de Villa $\mathrm{Pa}$ so desde hace décadas posibilitó seguir todo su derrotero por el proceso. Por eso invitamos al lector a revisitar

territarios 34

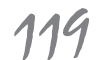


los textos de Rosana Guber en torno a lo que se entiende como trabajo de campo etnográfico, alejado de toda estandarización. De hecho, sibien este articulo reflexiona a modo de cierre de un momento en el desenvolvimiento de la investigación, en consonancia con los objetivos del proyecto mayor, a la vez abre a otras dimensiones de investigación.

${ }^{7}$ Hace más de cuarenta años que yo resido a dos cuadras del asentamiento, involucrándome personale intelectualmente con las familias que lo habita (ba)n.

${ }^{8}$ Según los entrevistados, el alquiler de una pieza con baño compartido, en el año 2013, en La Loma, rondaba los US\$ 100 mensuales. Este sistema de arrendamiento para trabajadores estacionales o permanentes, aún permanece, y seguramente persistirá, pues una de las arrendadoras de las habitaciones es propietaria legal del terreno y la vivienda. Su marido trabajaba en una empresa constructora de Mar del Plata y falleció en un accidente laboral. A modo de indemnización, la empresa le procuró la legalidad del terreno y le construyó la vivienda de material (Comunicación personal a M., en La Loma).

${ }^{9}$ Se entiende la territorialidad como la imbricación

territarios 34 el sistema de arriendo (incluyendo habitaciones) esté regulado hasta hoy, etc. ${ }^{8}$. En otras palabras, una confluencia de intereses, territorialidades ${ }^{9}$ y temporalidades diversos, organizados en un lugar específico, donde producir y reproducir sus condiciones sociales y materiales de existencia. Todo ello, poco o nada tiene de irregular sino que, por el contrario, es un espacio regulado por distintas temporalidades, especialmente por el tiempo del trabajo, y diversas legalidades, $\mathrm{o}$ formas de vivir la relación con la tierra, que confrontan, coexisten e interactúan con la propiedad privada. Por cierto, a lo largo de este trabajo de campo, rara vez emerge 'la villa' y solo para referenciar algún proceso de violencia o un lugar del habitar con pavimento, fiestas y sin inundación, y sí La Loma, un topos específico que privilegia una espacialización. Por ello, frente a conceptos clasificatorios cerrados, se prefiere la noción de 'formas socioterritoriales de apropiación del habitar' (Núñez, 2011c) que entrelaza, imbrica, apropiación y habitar en el sentido que le da Lefebvre (1971, 1972), ya que “[...] habitar es apropiarse de algo [...] en contraposición al concepto de hábitat, instaurado como suma de presiones por la racionalidad estatal $[. .$.$] habitar es tiempo$ cercado en un espacio [...]" (figura 1).

Figura 1. Espacialización de uno de los censos de las familias de Villa Paso, 2003 ${ }^{10}$

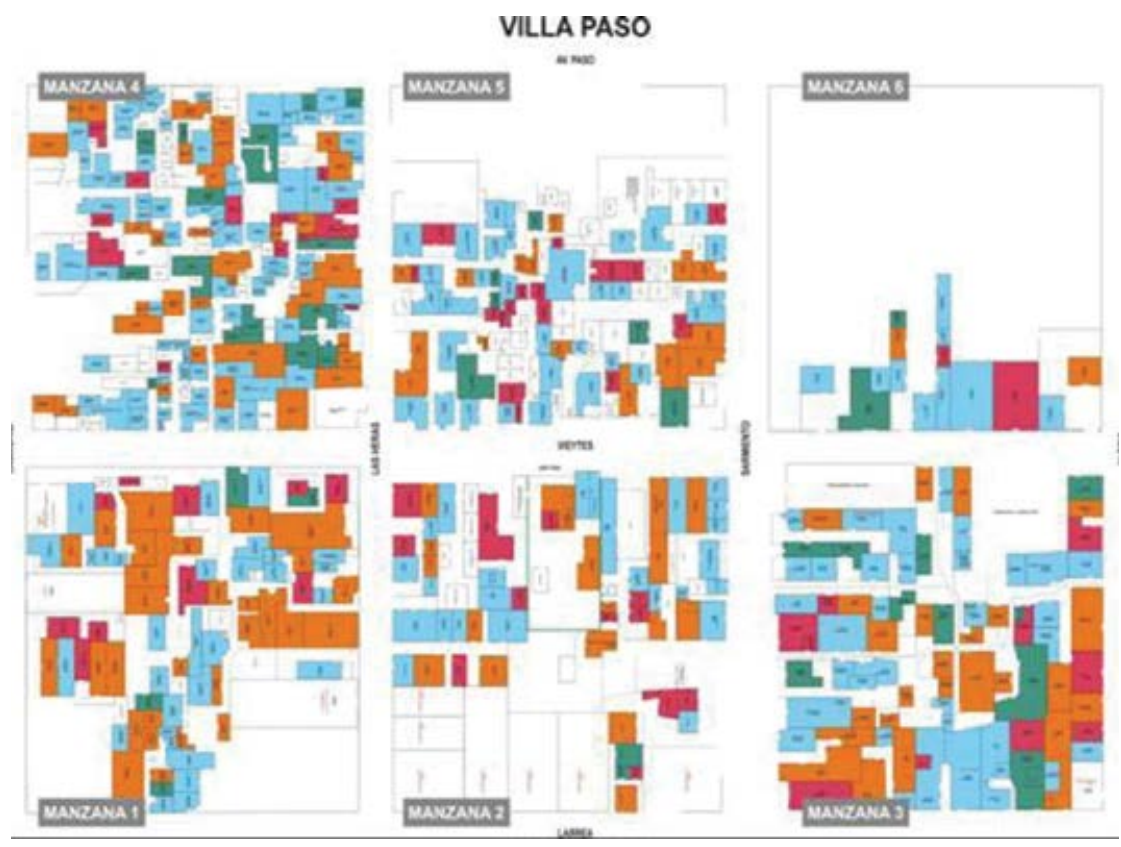

Fuente: Municipalidad de Gral. Pueyrredon, Departamento de Promoción Social. 
Esta forma socioterritorial emplazada en la zona más alta de la ciudad, otrora una cantera abandonada, y hoy uno de los barrios social y económicamente más valorizados, que la cobija en su centro, pone de cabeza y problematiza, desde su misma génesis, la relación establecidos-forasteros de Elías (2003), como se verá un poco más adelante $^{11}$.

Remitiéndose a la segunda relocalización, cuyo proyecto se lanza en 1998, se escucha decir en La Loma que fue promovida por el Sheraton, complejo hotelero de cinco estrellas emplazado a pocas cuadras de allí; y también por las protestas de los habitantes circundantes, sobre la desvalorización inmobiliaria que el asentamiento provocaba. Sin descartar estos argumentos, no dejan de ser un juego de intereses siempre presentes en las disputas por la apropiación del espacio urbano. A los efectos de no quedar entrampados en tan simples y evidentes causas, se intentará en este texto mostrar otros observables, generalmente ocultos detrás de la materialidad de los objetos.

Fue precisamente en ese año, 1998, en una ocasión en que dábamos una charla sobre la apropiación del espacio en Mar del Plata, cuando alguien del público nos preguntó qué opinábamos de dicho proyecto de relocalización. La exposición de los argumentos, sólidamente fundados en contra de este, motivaba la salida del aula de algunos oyentes, claramente incomodados. Al día siguiente, nos citan en la municipalidad, por parte del Secretario de Gobierno, quien habría sido el mentor de tal proyecto. De nuestra reunión, solo diremos que fue un 'diálogo de sordos', que finalizó con un molesto “ ¡Usted pretende una reforma urbana y yo tengo que hacer esto en los cuatro años que dura mi gestión!" Soberbia e ignorancia entrampadas en el fetichismo de la mercancía, que reproducen la política urbana como un producto tecno-burocrático materializado en objetos. Pero ocurre que la relación de la población con su lugar de vida es una de las áreas donde planes, programas y proyectos, acciones de ingeniería social y violencia, operan de la mano de teorías configuradas como políticas urbanas, desenraizadas de las prácticas sociales efectivamente operantes (Núñez, 201lc). En otras palabras, no nos permitió llegar a decirle que $s u$ proyecto de relocalizar, ya en ese momento, tres generaciones de habitantes, era tan sólo una ilusión... ¿ ¿estatal? ${ }^{12}$.

\section{La explosión del espacio}

En una nueva faceta de la estatalidad de fines de la década de 1990, se improvisa una nueva expropiación a la territorialidad social de la segunda y tercera generación de los habitantes de la denominada Villa Paso. $\mathrm{El}$ ¿debate? se circunscribe a personificaciones de pequeña burguesía acomodada, del campo político burocrático y de intereses corporativos (Núñez, 2010), es decir, en la territorialidad burguesa de la estatalidad profunda.

Entre ambiguas y contradictorias representaciones del espacio, reificadas en identitaria y epistémicocultural de los distintos espacios sociales de pertenencia, de los que el espacio geográfico es parte constitutiva. Ver Núñez (2011, 2012).

${ }^{10}$ Los colores del plano remitían a la cantidad de dormitorios que requerian lasfamilias en las viviendas de destino. Esta necesidad se materializó en otra ilusión estatal, dada la cantidad de años transcurridos entre este relevamiento y el traslado de las familias. Las familias crecieron, se formaron nuevas, se allegaron otros familiares y no familiares, dinámica no concebida ni reconocida por la burocracia que abonaba, irónicamente, la denominada por ella misma "guerra por las casas".

${ }^{11}$ En trabajos anteriores (Núnez, 2011b, 2011c) analizamos las relaciones de poder y la interdependencia entre los grupos, junto a los aparatos del Estado, que confluyeron en una primera expulsión de los establecidos en La Loma, en 1970, a partir de la iniciativa de los forasteros circundantes, propietarios, y lo entrelazamos al proceso de la segunda expulsión, cuyo proyecto, aun hoy inacabado en su materialización, comenzó en el año 1998, analizándolos como dos momentos de la lucha de clases. Aquella $\Rightarrow$

territarios 34 
primera relocalización la pudimos reconstruir a partir de la prensa escrita y fue un hecho completamente elidido de la memoria local.

${ }^{12}$ Lefebvre (1972, p. 156 y ss.) postula que la ilusión estatal, junto a la filosófica, se balla vinculada a lo que denomina ilusión urbanistica. Ilusión en tanto pretende reemplazar la práctica urbana, que no la estudia puesno la ve. Es un urbanismo de clase, que oculta una estrategia de clase, y que implica un doble fetichismo: a) el de la satisfacción, sobre la falsa hipótesis que es posible conocer y clasificar las necesidades y proporcionarles un objeto; $y$ b) el del espacio, no logrando resolver el conflicto entre el uso y el intercambio, incluso cuando oprime al uso y al usuario.

${ }^{13}$ Esos conflictos desatados en cada uno de los barrios de destino de los habitantes motivó que el entonces intendente difundiera la consigna de que "los que se asienten tendrán certificado de buena conducta $y$ averiguación de antecedentes de la policía. Estamos baciendo un relevamiento para determinar quién es quién” (La Capital, 2003).

${ }^{14}$ ExSecretario general de la UOCRA Mar del Plata, y de la CGT local, ExConcejal por el Partido Justicialista,

territarios 34 mapas, censos y registros, a lo largo de cinco años, se intentó conformar, en el año 2002, una Comisión con los habitantes de La Loma, con delegados por cada manzana, para analizar los lugares de destino, pero se disolvió a los seis meses, por conflictos y falta de acuerdo entre los habitantes de La Loma, pero también entre los residentes de los barrios de destino (Núñez, 201lc) ${ }^{13}$.

Finalmente, el 23 de julio del 2003, es aprobado el Sub Programa Bonaerense IX-Dignidad, bajo la modalidad de un Convenio entre el IPV, la MGP y una asociación intermedia, la ONG Trabajar, presidida por J.T ${ }^{14}$, lo que motiva nuevos censos, registros y relevamientos... de no todas las familias:

Porque los asistentes iban y entraban a ciertas casas, no entraban a todas las casas. [...] porque la zona donde estábamos nosotros, somos todos parientes ¿iviste? y yo te puedo asegurar que era toda gente sociable y jamás, desde que estuvimos ahí, jamás entraron las asistentes. Fueron a ciertas casas, así, pero no [...] y decían que no entraban porque los agredían (Comunicación personal a R., 2011).

\section{Contradictoriamente, el Sub-Progra-} ma IX-Dignidad contemplaba, como se dijo, la construcción de 500 viviendas, dispersas en tres barrios distintos de la ciudad, para adjudicarlas, según uno de los censos, a 398 familias de un asentamiento, mientras que un relevamiento realizado por los propios habitantes contabilizaba 700. Al respecto, se señalarán algunas dimensiones importantes para lo que sigue en este artículo: (a) la diferencia numérica entre el censo oficial y la cantidad de viviendas a construir, se debió a que la resistencia de habitantes considerados establecidos legítimos en los barrios de destino se desdibujó cuando el gobierno local decidió ceder un porcentaje de las viviendas a construir a familias en situación de precariedad habitacional de esos barrios; (b) las condiciones urbanísticas (servicios de infraestructura, equipamiento colectivo, accesibilidad, inundabilidad) son sumamente diferentes en los tres barrios, pero inscritas claramente, por su localización, (sin espacialización, diría Lefebvre, 1976,) en un proceso de segregación forzosa ${ }^{15}$; (c) el compromiso explícito de los empleados del gobierno a cargo, y del propio intendente, de la distribución de las familias separando 'la gente mala', de 'la buena'; y (d) la condición de habitar en La Loma en el momento del censo, y en el momento de salir. Es decir, se dio, no linealmente, lo que Elías (2003) denomina sociodinámica de la estigmatización, pero promovida y reproducida, indistintamente, por establecidos-outsidersgobierno, inter e intra familias establecidas, inter e intra outsiders, y así para adelante.

Pero las distintas temporalidades presentes en La Loma también atentaban contra la organización colectiva. Todas y cada una de las viviendas levantadas en las seis manzanas que se muestran en la figura 1 , de una u otra forma, fueron construidas al ritmo del reloj del trabajo capitalista. Un remolino de cientos de botas blancas derecho al pescado a las cinco de la mañana bajando al puerto; las bicicletas a las ocho, 
bifurcándose a las pocas cuadras, según el destino de la obra en construcción; arco iris de alpargatas y zapatillas a las diez, camino a limpiar casas burguesas o a cocinar en los restaurantes del centro; moños negros y sacos al tono a las cinco de la tarde, desapareciendo hacia el imponente casino. Eso sí, todos en grupo. Pero cada uno a su ritmo, para trabajar y dormir. Claro que también había personas o familias que iban y venían de la ciudad y entonces les convenía alquilar alguna casilla o alguna pieza, según la época laboral. A los que les iba mejor, pudieron comprar un terreno, pero muy lejos, para invertir, simplemente. Porque La Loma quedaba cerca de todo y no había que gastar en transporte. O sea, La Loma no fue su única alternativa, como dice la bibliografía dominante, sino la mejor, por varias razones.

Todo el proceso de licitación, construcción, adjudicación y traslado de las familias, que comenzó en el año 2006 y aún no ha finalizado, permite no solo hacer observable el conjunto de dispositivos de heteronomía puestos en juego por las distintas expresiones de la estatalidad sino los intereses de las personificaciones que lo protagonizan, permeados por múltiples formas de violencia, corrupción e impunidad por parte de las fracciones sociales dominantes, pero que además se normatizan como, por ejemplo, la Ordenanza N. ${ }^{\circ}$ o- 11306 que exceptúa del cumplimiento de las normas de habitabilidad de todos los programas oficiales de viviendas de interés social a los que adhiera el municipio ${ }^{16}$.
A dos años de haberse iniciado la construcción del Programa Dignidad, un alto porcentaje de las viviendas de los barrios Las Heras y El Martillo fueron abandonadas, semiconstruidas, por la empresa constructora, reclamando mayores costos ${ }^{17}$.

Paralelamente, el municipio abrió un registro de demanda habitacional (Ordenanza 18518) que, arbitrariamente, se congeló cuando hubo 7000 familias inscriptas, para viviendas que se construirían en los barrios Belisario y Bosque Grande, como parte del Plan Federal. En palabras del subsecretario de Planeamiento Urbano:

En el registro que implementó el Municipio, hasta que se decidió suspenderlo, se inscribieron unas 7 mil familias que no tienen vivienda; sin embargo, consideramos que hay otras 3 mil que tienen ese mismo problema; es imposible pensar que semejante déficit pueda ser resuelto de la noche a la mañana (La Capital, 2009).

Al 20 de febrero del 2009, podía leerse en la puerta del Departamento de Promoción Social "A partir del 20 de marzo se brindará información sobre la modalidad de reapertura".

Se despliega así otro aspecto: la promesa, conformando un vínculo social que obstaculiza la autonomización de la población y consolida la obediencia pasiva y anticipada. "Una fórmula cómoda para quien no sufre el problema en la propia piel y lo 'resuelve' declarando que no tiene solución. Un pasó más, y el problema 'resuelto' es asesor del Ministerio de $\mathrm{OO}$ y sspe de la Pcia. de Buenos Aires, y reconocido como "la mano derecha de Aldrey Iglesias", quien es propietario de varios multimedios, $y$ de la cadena hotelera nh, apodado "el patrón" y es quien realmente gobierna la ciudad desde la década de 1990.

${ }^{15}$ Sintéticamente, se dirá que fue un proceso de expulsión deliberada de la población, encubierta por la construcción y legitimación, a lo largo de todos esos años, de un discurso multiactoral, pero reforzado por las prácticas delgobierno, sobre el consenso y la inevitabilidad del traslado (Núñez, 2011a).

16 Esto "amparó" que se escatimen materiales, además de su pésima calidad, y que ninguna de las casi 30 actas de infracción por la mala calidad de las viviendas sea tomada en consideración.

${ }^{17}$ En realidad, la empresa se dedicaba a desagotes industriales, y nunca habia construido viviendas. "Todavia no sabemos qué empresa trabaja acá, pero sabemos para quién trabajamos... algo tiene que ver el capo de la UOCRA. Está un poquito metido todo..." (Entrevista a un obrero en Plan Dig-

territarios 34 
nidad, del $B^{o}$ Las Heras). Asimismo, el 24/08/2005, el Secretario de asuntosgremiales de la UOCRA, envía una denuncia a Jorge Trujillo sobre el despido de todos los trabajadores en blanco de la obra, quedando sólo los que estaban en negro. tersitarias 34 lanzado directamente para el olvido" (Weffort, 1978, p. 10, trad. propia).

Otra dimensión que merece ser tomada en consideración es la permeabilidad de los clivajes discriminatorios que envuelven la vivienda popular por parte de la tecnoburocracia y que precondiciona el doble fetichismo de la ilusión urbanística y la ilusión estatal (Lefebvre, 1972), ahondando la contradicción entre el valor de uso y el valor de cambio de la vivienda, lo que motiva que un alto porcentaje de estas viviendas no esté ocupada por los beneficiarios originales. Es decir, el hacer sin reflexión, el 'hacer no se sabe cómo' de la burocracia, produce planos e ideas sin participar del mundo material a ser representado y viviendas impuestas que no satisfacen las necesidades de la población, y son mercantilizadas (Núñez, 2010; 201la). Sin embargo, dice Lefebvre (2013), la vida cotidiana no puede comprenderse sin esta contradicción entre valor de uso y valor de cambio, pues es el uso político del espacio lo que restituye al máximo el valor de uso: recursos, situaciones espaciales, estrategias.

A su vez, el registro de emergencia habitacional para las viviendas del Plan Federal se nutre de especificidades sociales que deben reunir los posibles 'adjudicatarios' (Decreto N. ${ }^{\circ} 750$ ), constituyendo, así, un espacio concebido. Sin embargo, ese mismo decreto establece que cuando los "aspirantes" superan la cantidad de viviendas disponibles, "a condiciones equivalentes", un criterio adicional es "el tiempo de atención en el servicio social". Entonces, como se dijo, es un espacio-tiempo concebido que se entrelaza a..., transformándose, mutuamente, el espacio vivido y percibido, pero sin relación lineal ni mera reacción clientelar.

En la figura 2 puede verse la contradicción entre el espacio-tiempo concebido y las prácticas espaciales, sumado que, ante la paralización del Dignidad, los funcionarios

Figura 2. Explosión del espacio: fisuras en el espacio concebido

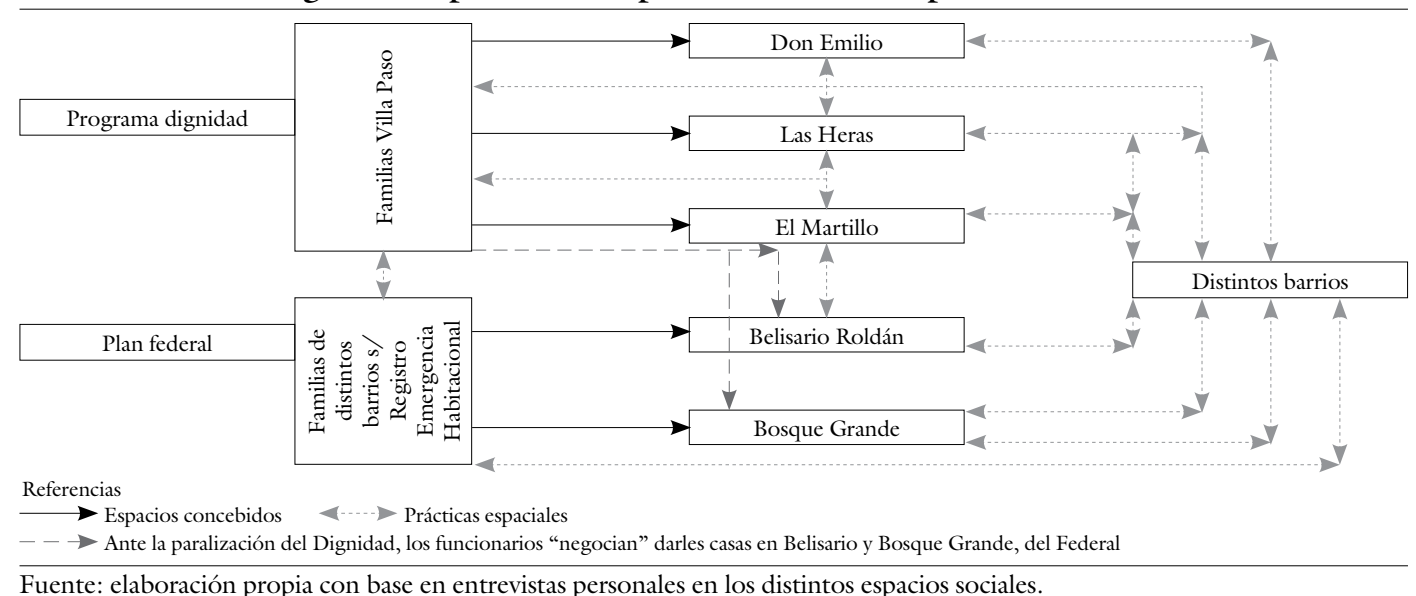


negocian darles casas en Belisario y Bosque Grande, del Federal.

Esta explosión del espacio, que ofrece solo indicios esquemáticos de la complejidad que adquieren estas migraciones interbarriales, propone fisuras en el espacio concebido; aquello que escapa del rígido control de la dominación por los aparatos burocráticos; que lo conocen pero hacen como si no. Por eso, cada acto oficial de entrega de casas a los 'adjudicatarios' legítimos, con la presencia del intendente, respeta el rutinario acompañamiento de la asistente social con la llave en la mano y un imperativo al oído "metete y no te salgas, que te la usurpan" no sin antes entregar el "Manual de recomendaciones para beneficiarios", con órdenes respecto de cómo higienizar y ventilar los ambientes, cómo distribuir los integrantes de la familia según sexo y edad, distintas prohibiciones sobre uso y modificación de las viviendas, y reglas de convivencia, para finalizar "alertando" que pasaría un tiempo hasta la 'adaptación' y que, para ello, "contaban con el acompañamiento". Sin embargo, se recuerdan las palabras de los entrevistados en cuanto a que:

Las asistentes de la municipalidad han venido y nos han tirado así nomás...Chau, se olvidaron, se olvidan... Cuando vinimos, solamente el día que estaba listo nos han traído con el camión, nos han dicho "esto es de ustedes". Eso ha sido todo y agarralo si querés ¿y...? Somos humanos, somos gente...no somos chanchos" (Comunicación personal con B., relocalizada en Las Heras, 2009).
Ni siquiera volvieron las asistentes. A nosotros nos entregaron las llaves y ya está. Fuimos a la municipalidad, un montón de veces, pero nada $[. .$.$] dicen que ya hicieron$ el esfuerzo de hacer las casas y se lavan las manos (Comunicación personal con A., relocalizado en El Martillo, 2009).

\section{La mutua transformación ${ }^{18}$}

Casi todas las casas del Plan Federal han sido vendidas por los adjudicatarios originales, $\mathrm{y}$, algunas, hasta tres y cuatro veces, en poco tiempo. También varias del Programa Dignidad. No hay precio fijo, pues lo fija el que la vende y van desde los 10000 hasta los 30000 pesos, y no necesariamente todo tiene que ser en moneda, sino que intermedian objetos, de distinta índole. El vendedor, entrega junto con la casa la carpeta que le confiere la municipalidad y que pasa de mano en mano, junto a, no siempre, boletos de compra-venta truchos. "Y se vuelven [...] la que vendió acá, era del puerto; la que vendió allá, con la plata se terminó la casa en Santa Clara [...]" Azucena y su familia son parte de este proceso. A sus 65 años, hace siete que llegaron a Mar del Plata porque “en Tucumán estaba bravo el laburo [...] yo no conocía Mar del Plata porque nunca en la vida me alcanzó para vacaciones $[. .$.$] "$ Llegaron a esta ciudad, y fueron pasando de alquiler en alquiler, incluso junto a sus hijos casados. Hasta que una conocida les comentó de esta casa y la compraron. "Y en la municipalidad lo saben, porque vino un abogado a hacernos a todos un habeas corpus por si vienen los dueños." Pero
${ }^{18}$ A partir de este apartado, se entrelazan en un mismo relato las distintas entrevistas realizadas a lo largo del trabajo de campo en todos los barrios, con el propósito de evidenciar, justamente, la yuxtaposición de las distintas temporalidades sociales coexistentes, $y$ en tensión. Es decir, no aparecen aqui las citas de los entrevistados como texto aparte, sino que deliberadamente forman parte de la situación que las origina, narrada por nosotros y entrecomilladas sus palabras, como parte del bilo analitico-argumental, y llevando al lector en este tránsito hacia las reflexiones finales. Ver Guber (2013)

territarios 34 
quieren irse por la violencia que han sufrido en el barrio, y de la que ni siquiera los protegen, completamente, sus rottweiler. Sin los perros, "esto es tierra de nadie $[. .$.$] No$ sé de qué villa son, pero vos te das cuenta por la forma de hablar y de vestirse [...] son villeros". Pero, a diferencia de María, Azucena no la puede revender porque con lo que le dan no compra nada. Sin embargo, ella y todos sus hijos estaban anotados en el registro. "Pero nunca me llamaron [...] tampoco me borraron, pero para qué voy a reclamar si no me dan bolilla [...]" Uno de sus hijos también compró una casa del Plan Federal, y a los pocos días lo llamaron para adjudicarle una casa, en otro barrio, y la rechazó por la distancia. Azucena se disgusta porque " iMis otros dos hijos no tenían casa! $\mathrm{Y}$ yo no conozco a nadie para ir y hablarlo y que me hagan una palanca [...] que me pongan en la lista [...] algo".

Laura vivía con su marido y su hijo en un garaje que se le llovía. Pasó más de dos años yendo a la municipalidad en busca de una casa, haciendo cola desde las 10 de la noche, hasta las 8 de la mañana que la atendían y le daban uno de los 100 números que entregaban. Pero un día, bajo una lluvia torrencial, supuso que no iría nadie y aprovechó a dialogar cara a cara con la asistente que, hasta ese día, sólo le daba el número. “¡Vení a ver dónde vivo!” le rogó. $\mathrm{Y}$, así, como por arte de magia, a la semana siguiente estaba en su casa, lo que parecía un "sueño inalcanzable para poder escapar de la violencia familiar”. Empero, ahora el miedo es la violencia exterior, la del barrio, de la que culpa al municipio porque "acá hicieron un rejunte de todos lados y nos tiraron como chanchos en el río. ¿Por qué hicieron eso? O sea, mezclaron a la gente buena con la gente mala para que se maten entre ellos [...]" Más de una vez, se plantearon venderla e irse pero "no, nos hemos echado atrás porque una vez que la tenés, pensás en los hijos. Y entonces nos hemos organizado. La gente del grupo estamos todos en contacto, donde pasa algo a alguien, ahí estamos todos".

Virginia cirujeabay al no poder seguir en la casa de su mamá, con su pequeño hijo, fue al bajo de Libertad y levantó una casilla, sin baño ni agua. Hoy, "no puedo creer que hayan pasado así dos años [...]" Estaba inscripta en la municipalidad y pensaba que "todo saldría bien" porque tenía otros cuatro hijos “desparramados" con familiares, y una hija con enfermedad crónica. Pero se cansó de esperar, hasta que su madre le avisó que vendría la Presidenta de la Nación, le entregó una carta y a la semana tenía "a las asistentes sociales, que no podían creer cómo vivía...” Cuenta que allá, antes, era feliz. No tenía nada, pero la gente era diferente. En el Belisario, la asistente le prohibió cirujear, por la imagen del barrio. Entonces, "tengo que aparentar ser una persona que no soy. Eso es mucha presión, es bastante complicado. Yo no soy lo que aparento. Si hubiera podido elegir, no viviría acá, porque el Belisario es un desastre. Un desastre. Es un rejunte de toda la porquería de Mar del Plata. Somos todos lo peor de lo peor, aunque no lo seamos. Somos todos lo mismo..." Y a pesar que están en juicio contra la empresa constructora 
por que las casas "se vienen abajo, la suya se abre "para las reuniones de los cuatro locos que quieren hacer algo...".

A Moni, no entender por qué le decían que necesitaba una casa cuando lo que reclamaba eran materiales para terminar la que estaba construyendo, y siendo que había otra gente más necesitada que ella, lo descifra como "el consuelo de una lucha". Ella es parte de Los Sin Techo, y participó de todo el proceso de lucha del Pueyrredon (Núñez, 2010) pero como hacía muchos años que estaba inscripta en el registro, las asistentes le ofrecieron, junto a otras cuatro familias de la organización, una casa en el Belisario. Era "la casa o nada", le dijeron.

$\mathrm{Y}$ con el "desarraigo, la pérdida de tu lugar de 35 años, vamos con una vida hecha en otro lado". En la villa de cemento, como llaman al barrio, "se matan por ver quién manda, lo típico de ser villero por un día. Tenés gente de todos lados, gente de todas las organizaciones, partidos políticos, ONGs, todos quieren sacar partido de lo poco que hay".

Sin embargo, la tranquilidad "de tener una casa buena, de poder tener un baño, de poder bañarme, porque antes tenía el baño afuera, tener tu intimidad, tu privacidad, de que los chicos tengan su cuarto, nosotros tener nuestro cuarto", le permite a Moni constituirse en una referente de la lucha por la vivienda, y ser el nexo actuante con el Centro de Integración Comunitaria de El Martillo.

Jorge vivió en La Loma desde muy chico y se acostumbró. Recuerda que por los '90 su familia fue una de las primeras censadas, pero el tiempo pasó, se juntó, y las asistentes decían que tenía que ir a la nueva casa con sus padres. "No nos hicieron el desvínculo familiar..." Fue con su pareja a otros lados, tomaron tierra, pero finalmente volvieron a la villa, a una casilla de $3 \times 3$. Hasta que "para cuatro de familia, ya no se pudo..." Y aunque allá dejó todo y siente nostalgia, "anduve y ando mucho en la política y tocando algún que otro concejal, porque las asistentes no me la querían dar”, consiguió una casa del Plan Federal, no en El Martillo, donde le correspondía por ser del Programa Dignidad. Paradójicamente, quien les había cedido un lugar en el terreno para que levante la casilla, todavía espera en La Loma...

Jorge y su señora, con los chicos, ya no podían soportar el alquiler. Sus ahorros, habían ido a la compra de un terreno fiscal, ofrecido por un empleado municipal.

A todos los parientes de él le vendió terrenos. Y me llevó a ver a todos los parientes, y sí, todos tenían terrenos fiscales. Y el tipo dice que él mismo se encargaba de hacer los papeles del terreno, que primero se construía. Y una vez que tenían todo, le daban un papel.

Pero estaba todo inundado; y se lo cambia por otro, que "cuando lo fui a ver, estaba construido! Le reclamé, pero el tipo no apareció más." Vicente, conocido de un amigo de Jorge, ocupaba el campo de Carmona, como se conocía a los terrenos donde se levantaría el Dignidad en Las Heras. Para desocuparlo, le ofrecieron una de las casas a construir. Aceptó, y cuando llegó el momento le entregaron la carpeta, territarias 34 
como siempre. Cuando Jorge se contactó con Vicente, no dudó en comprarle la casa porque "lo que vale la casa real no te lo van a cobrar". La esposa de Jorge tenía que simular, ante la municipalidad, ser la sobrina de Vicente quien sólo les dio las llaves, mas no la carpeta. Pero, enseguida, la vida en Las Heras fue insoportable; no hablar con nadie era la regla, pero constantemente les decían: "ustedes no son de La Loma, nosotros nos conocemos todos y ustedes no son de allá..." Y la violencia explícita, con daños físicos severos a la esposa de Jorge, hizo que abandonaran la casa, introduciéndolos, nuevamente, en las penurias de la vivienda...“¡Arreglátelas!”, fue la respuesta de las asistentes de la municipalidad cuando expuso todo el proceso que había padecido, porque "oficialmente, la casa es de Vicente y, simplemente, te la había prestado".

En el Dignidad de Las Heras, Luis se siente inseguro, en todo sentido. Cada vez que va a la municipalidad a averiguar, le dicen "no, no, no, no está figurando como un barrio, es un baldío". Y necesita poner un kiosco para vivir, pero no puede, como tampoco puede entender por qué, si no le dan la escritura, tiene que pagar el agua, la luz, el gas...todo.

En La Loma no teníamos casa, teníamos la casillita que le llaman, y nos sacaron porque dijeron que acá íbamos a tener todo lo que tiene un hogar, y que no íbamos a pagar nada, y resulta que ahora van a empezar a venir las cuotas...Han tardado tanto en relocalizar, que de una familia sacaron 5, 6 familias...Todo mal hicieron la municipalidad y las asistentes...Pasaban los gobiernos y jamás nos sacaban...Yo viví miles de años ahí..." (Entrevista a Luis, relocalizado en Belisario)

En cambio, Roque sí puso el kioskito en su nueva casa, dividiendo el comedor con una madera. "Sin permiso, ni nada, total, acá nadie viene." Nunca se quisieron ir de La Loma, pero una señora rechazó la casa del Dignidad, y los sacaron "de un día para el otro".

En La Loma vivíamos tranquilos y acá no podés...no sabemos con quiénes estamos conviviendo. De La Loma elijo todo... Era otra crianza para los chicos, no se juntaban con nadie y acá... acá hay malajunta. Vivíamos bien, con gente trabajadora y acá vivimos encerrados, enrejados...Yo no quería venir, yo no quería venir..." Las fiestas ya se perdieron. Porque antes "era todo familia, y ahora es cada uno para cada uno. Ahora al vecino le molesta el ruido, acá cambiaron, están entreverados, se pelean, discuten...entre los que vivían por Vieytes, y los que vivían por Sarmiento... (Entrevista a Roque, relocalizado en Las Heras).

Era todo familia pero, como dice Bourdieu, como cuerpo y como campo cuando el deseo de volver a La Loma aparece como posible si se recupera lo que está en juego: los papeles. Pero, el problema es que "nadie sabe dónde están, pero todos sabemos quién los tiene...".

Silvia está casada con el tío de Roque, pero a ellos les tocó El Martillo. En La Loma vivían bien, ella durante 20 años, y él, 45, y lucharon para quedarse. Pero su mundo era otro mundo; un mundo de encierro. Sus cinco hijos son adoptados, y vivió siempre 
con la presión de Tribunales y la exigencia de mudarse a una casa mejor. Pero "esta casa no es mía, sigue siendo de ellos... nosotros somos guardadores", hasta que pasen 10 años. Y quiere agrandar la casa, poner una verdulería, pero no la dejan. Está prohibido por el acta. Es agente sanitaria y desde el primer día que llegó al barrio, no para de luchar y reclamar por el estado de las viviendas y del barrio, aunque no encuentra mucho eco en sus vecinos. De todas maneras, por su trabajo para médicos comunitarios, tiene que hacer encuestas y eso le permite un contacto más cercano y cotidiano con la gente, y ver caras que no son de Villa Paso, y volverse con la impotencia de no poder saber cómo la consiguieron o a quién se la pagaron.

Nelly, en cambio, a sus 91 años, es el cuerpo más férreo del encuentro-desencuentro espaciotemporal en yuxtaposición: se dedicaba a actividades rurales en el corazón de una ciudad que hacia 1940 crecía sobre lo que se creía era el progreso urbano. $\mathrm{Y}$, todavía hoy, vive aferrada a su rol de cuidadora esperando que "algún día venga alguien, golpee las manos y me diga 'soy el dueño'...”, aunque no comprende por qué ya no le pagan. Se resistió a las dos opciones que le dieron las asistentes sociales: una casa en Las Heras, o al geriátrico.

Mary también hace más de 50 años que está en La Loma, y aunque ya ganó tres instancias judiciales, no logra tener el título de propiedad del lote, lucha en la que ya lleva 15 años, desde que le llegó la nota de desalojo. "Pero los abogados no me quieren dar el título de propiedad porque aparentemente se quieren quedar ellos con el terreno". La incertidumbre de Mary se agudiza porque ya no puede pagar más a los abogados. Pero se consuela porque tiene un informe que certifica que los árboles plantados en su terreno tienen "el mismo tiempo que yo ahí, cuando mi marido levantó la casilla en la vereda de sol y los plantó". El recuerdo se interrumpe para contarnos que

Los chicos de enfrente, ayer no estaban. ¿Ves que hay ropa tendida? Bueno, ahí no había quedado nadie y de la mañana a la noche ves gente. Acá atrás, también, no había nadie, y de la mañana a la noche encontrás gente y ropa tendida ¿̇de dónde aparecieron? $\mathrm{Na}$ die sabe... Pero no nos relacionamos, es un mundo aparte. (Entrevista a Mary, aún en Villa Paso).

Para Jorge, la pelea de Mary "es un sueño mal soñado". Él vino hace veinte años de Misiones y fue varias veces censado. Pero siente que las asistentes tienen un trato discriminatorio, porque "nunca entraban a la casa". Con el tiempo entendió que "en la presión, la multitud hace la fuerza", y él era solo. Y espera. Entre escombros, pastizales, suciedad, roedores...condiciones inhumanas apenas interrumpidas por el calor del mate que nos acerca.

Fueron varios los días en los que Mario, que hoy vive en El Martillo, interactuó con nosotros en todo este espacio social. Podríamos decir que él se apropió de esta investigación colectiva a la vez que se apoyó en nuestra entrada al campo para ir "des- territarias 34 129 
pertando conciencias porque hay gente que entiende muy poco". En su nueva casa, planea crear un espacio como "una especie de oficina para generar trabajo, un centro de trabajo para hacer de todo, y así cuidar a los chicos que no agarren junta, porque yo lo viví de chiquito en la villa y no me gusta ¿viste?”

Cuando vivía en La Loma, hubiera podido comprar el lote que ocupaba pero había otras seis familias, entre ellas la de su madre, y no quiso desalojarlas. "Pero bueno, ¿viste? por algo no pasó. Yo sé que las cosas no pasan porque el destino quiere así ¿ंviste? No podés modificar el destino”. Todo le trae malos recuerdos; y de su vida en la villa poco quiere acordarse. Sin embargo, Mario va recordando y contando su vida, aunque no pueda precisarlo en el tiempo, no puede datarlo. "Vi mucha gente morir...es una vida que no se la desearía a nadie... a nadie". La libertad de la coacción frente al sufrimiento, sólo la pudo materializar construyendo una casilla para él y su primera pareja, donde fue censado inicialmente. Pero al separarse, lo "sacan" del censo porque rehace su vida con otra mujer fuera de La Loma. Sin embargo,

Como mi vieja siempre andaba con políticos y la asistente social, me anotaron de nuevo. Y tuve que volver a la villa para que no me saquen de vuelta...siempre hacían promesas y...yo siempre fui a las reuniones así cuando prometían y era todo político ¿viste? como yo a los políticos...mi vieja se sentaba con los políticos, y yo siempre los miraba, porque no me gustan ¿̨viste? te soy sincero, los políticos no me gustan...esteee.....y bueno, hasta que surgió el día... el día que yo creí...y pudimos elegir El Martillo por mi vieja... (Entrevista a Mario, relocalizado en El Martillo)

O los borraban del censo, o tenían que ir todos los días a la municipalidad, con algún regalo de por medio para las asistentes, pero sin que nadie los viera, y entonces "si para ellos nosotros éramos como chanchos, ellos eran unas ratas". Así que, en esta silenciosa complicidad, todos se igualaban en un mismo y mutuo proceso de deshumanización, porque en esta acción, se transfiguran las personificaciones de burócrata y villero sin saber muy bien, al final del día, quién es quién.

Y los relatos siguen ese movimiento de las prácticas espaciales, también con quienes aún viven la incertidumbre de “ ‘a dónde nos irán a llevar...?” En la figura 3, vemos a Rosario esperando el día en que le digan "ya está la casa, venimos a llevarte". A ella, como a tantos otros, un cuidador le dio permiso para hacerse una piecita en el lote. Ahora recapacita que nunca hizo nada para quedarse con el terreno, porque si no, "ya sería dueña". Aunque no se trataba mucho con nadie, conocía a todos los de La Loma por el trabajo en las pesqueras. La asistente le dijo "'vos tenés para el Martillo', pero se habían terminado; después le dijo 'vos tenés para los dúplex en Las Heras' (figura 4), se terminaron; y

Después a lo último ella vino y me dijo 'te toca para ese lado', bueno. A mí no me gustaba mucho el dúplex, pero ¿sabés por qué 
Figura 3. El espacio vivido en La Loma, por cuatro generaciones habitar

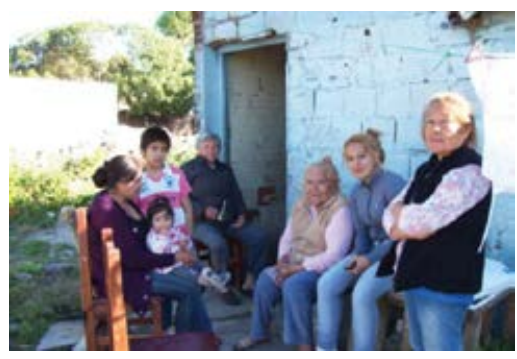

Fuente: archivo personal.

Figura 4. El espacio concebido, sin “¿a dónde nos irán a llevar?”

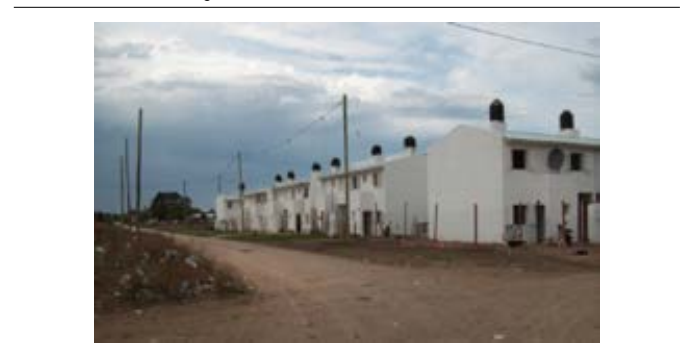

Fuente: archivo personal

me daban el dúplex? Porque en ese tiempo estaban casi todos los chicos míos... (Entrevista a Rosario, aún en Villa Paso).

La incertidumbre de "¿a dónde nos irán a llevar?" motiva la reflexión de María que, también en la figura 3 , "me quedaría si me mejoraran la casilla". Tiene un primo que alquila una pieza enfrente de donde vive ella,

Porque la señora vive ahí, ella tiene piezas para alquilar. Entonces mi primo viene, alquila, trabaja y se va. Viene los tres meses y se va porque tiene su casa en las Termas...y qué casa! Allá en Santiago es reconocida la villa, en Santiago la re-conocen todos. Y se cuentan porque en esta villa se criaron mucha gente de allá, y por la tele lo pasan... (Entrevista a María, en Villa Paso, subrayado nuestro).

¿Dónde se ubica, en el proceso de producción del espacio, esta dimensión y expansión virtual de La Loma? Lo próximo y lo distante, la presencia y la ausencia, en la producción del espacio, tienen una coherencia apenas ficticia. Tan ficticio como lo paradojal de un espacio concebido, regulado, homogéneo y dominado por la tecnoburocracia y no apropiado, en el sentido de transformado por las prácticas sociales, y donde predomina (aun coexistiendo) el valor de cambio por sobre el valor de uso (Lefebvre, 1976, p. 131). Sirva como síntesis el espacio percibido que emerge de la lectura conjunta de las figuras 3 y 4 . En efecto, la mirada parcelaria y fragmentada de estas imágenes, es ilusoria, pero es la mirada hegemónica, toda vez que es la que abona como obstáculo epistemológico las políticas de vivienda. No hay un espacio concebido de un lado, y un espacio vivido del otro. El espacio "es" dialécticamente concebido, percibido, vivido (Lefebvre, 2013 , p. 388 ), como intentamos mostrar a lo largo de este trabajo.

\section{Reflexiones abiertas}

Como demostramos en un trabajo anterior (Núñez, 2013b), entre los años 2006 y 2012, pleno auge de estos movimientos de 
relocalización de población, el área central de la ciudad, que históricamente actuara como foco de irradiación de valorización económica del espacio, tuvo una tasa anual de valorización del suelo de 0,12 , contra un promedio de 0,23 para la ciudad en conjunto, y $\mathbf{0 , 4 5}$ la zona oeste-sudoeste, de barrios populares, de peores condiciones de habitabilidad y donde se localizan, desde el año 2005, los conjuntos de viviendas sociales del Plan Federal, Plan Dignidad, y por cooperativas. En efecto, en términos relativos, la periferia se nos aparece como la que menos ha incrementado los precios del suelo, pero si tomamos como referencia el año 2006 como base, más que triplicó el promedio de la ciudad en su conjunto.

En este horizonte de incertidumbre radicaly de irreversibilidad temporal (Abramo, 2010) resulta imperioso avanzar en el conocimiento para no reproducir políticas que profundicen la desigualdad social y urbana, ya que la instrumentalización del espacio mantiene y reproduce las relaciones sociales propias del capitalismo, o sea, las relaciones de explotación y dominio, dispersando la clase obrera, repartiéndola en lugares asignados, controlando el espacio y de forma tecnocrática la sociedad, dice Lefebvre (1976, 2013, p. 383).

Empero, cuando indagamos en la explosión del espacio, se rompe con el tiempo abstracto, homogéneo, en el sentido que introduce una fisura reflexiva, como el devenir lefebvriano, donde las tensiones y contradicciones del presente pueden abrir a su transformación. Es, como dice Acevedo (2011, p. 3) el tiempo en el que se juega la politica. En muchas de las casas de los protagonistas que nos acompañaron aquí, se transforma su materialidad concebida para gestar políticas para el barrio, para los pibes, y para quienes tienen otras necesidades, al recuperar en el presente un pasado mediado por la coacción pero, también, en el que se resignificó una lógica burocrática cotidiana como estrategia política. El espacio concebido comienza a transformarse en el percibido, es decir, en los relatos de la explosión del espacio, en mayor o menor grado, el regreso al pasado hace posible el cambio y no sólo la permanencia. Por eso, no hablamos de una política de vivienda, sino de cómo la política se construye, no sin tensiones, por, en y con las viviendas. La estatalidad es y ha sido una constante en la vida cotidiana de nuestros compañeros de campo, bajo distintas personificaciones del orden social, adquiriendo su síntesis más acabada en el espacio-tiempo concebido, $\mathrm{o}$ en la representación del espacio destinado a las (re)localizaciones, pero en articulación con el espacio vivido, que no es sólo físico, sino las prácticas sociales y políticas que lo producen, imbricadas a los espacios de representación. En efecto, la problemática del espacio vivido, dice Lefebvre (1976, p. 27), es un aspecto importante, esencial del conocimiento de la realidad urbana, pues la problemática del espacio se vincula a la problemática de la sociedad en su conjunto.

Analíticamente, pudimos elucidar cómo, en este presente tensionado por las distintas temporalidades socio-espaciales, las contradicciones y conflictos, riqueza y miseria, reproducción e invención, en térmi- 
nos de Lefebvre, se gestan históricamente, pero no se cosifican. Es decir, hay residuos no contemporáneos que alimentan esa contradicción del espacio entre coacciones del habitar y vivencias de libertad, y que dan sentido a la praxis (Lefebvre, 1976), a los espacios de representación. Sin embargo, aun cuando el hombre viviente es el verdadero sujeto del devenir, alrededor de él, encima de él, las abstracciones toman una forma extraña: los Fetiches. El fetichismo es a la vez un modo de existencia de la realidad social, un modo real de la conciencia y de la vida humana, y una apariencia, una ilusión de la actividad humana (Lefebvre, 1971, p.100, subrayado nuestro). Pero la brutal deshumanización, sostenida por el fetichismo de la mercancía como esencia de la lógica burocrática, emergente en varios relatos, cosificando al sujeto como un instrumento, torna a la alienación de teórica a práctica, y bace que el hombre se oponga a lo inbumano en el Derecho, la Moral y la Religión (Lefebvre, 1971, p. 164). O, en otros términos, con la propiedad, la estigmatización, y el sacrificio y la resignación, impidiendo rescatar del pasado el germen de la dominación, y permaneciendo oculto el momento social originario de construcción de la norma (lo permitido y lo prohibido, lo bueno y lo malo, lo sano y lo patológico, lo legal e ilegal, etc.), cuya base está determinada por un conjunto de situaciones estratégicas que definen y reproducen el orden social. Así podríamos interpretar, con Lefebvre, que los desencuentros espacio-temporales en la praxis truncan la realización de lo posible, pues, como ya dijera Marx (1998, p. 17) "Los hombres moldean su propia historia, pero no lo hacen libremente, influidos por condiciones que ellos han elegido, sino bajo las circunstancias con las que tropiezan inexorablemente, que están ahí, transmitidas por el pasado". En este contexto, la (re) (des) localización, podría ser caracterizada, siguiendo a Piaget y García (1984, p. 81), como una pseudo necesidad, como un fenómeno que se ubica en los primeros niveles de la génesis del conocimiento y que expresa la dificultad de imaginar otros posibles diferentes, sin poder diferenciar entre lo real, lo posible y lo necesario. En otras palabras, y parafraseando a Muleras (2008, p. 14), se podría decir que esta ¿política? urbana "encierra disputas por el monopolio de atribución de las significaciones de los objetos representados en el dominio epistémico, y la instalación de una lógica delimitante de las condiciones de reflexión y comportamientos", destruyendo los espacios diferenciales, intentando imponer en una rígida y única forma, una multiplicidad heterogénea de contenidos de apropiación del habitar. Pero cuando las prácticas espaciales hacen estallar la representación del espacio, es decir, el espacio concebido, quebrando la obediencia pasiva a la burocracia, los espacios de representación son fetichizados con la imaginaria orden de "metete y no te salgas, que te la usurpan", pretendiendo ilusoriamente romper la dialéctica de la producción del espacio. En otras palabras, los conflictos entre fuerzas sociales, al tener efecto y lugar en el espacio, se convierten 
en contradicciones del espacio (Lefebvre, 2013, p. 397).

\section{Referencias}

Abramo, P. (2010). La ciudad com-fusa. Mercado y producción de la estructura urbana en las grandes metrópolis latinoamericanas. EURE, 38(114), 35-69. Recuperado de: http://www.scielo.cl/ scielo.php? pid=S0250-716120120002 00002

Acevedo, M. (2011). Crítica a la 'ontologia del presente' en Benjamin y Althusser. Revista Pilquen 14(XIII), 1-11.

Borges, A. (2003). Tempo de Brasilia. Etnografando lugares-eventos da politica. Río de Janeiro: Relume/Dumara/NuAP

Clichevsky, N. (2003). Pobreza y acceso al suelo urbano. Algunas interrogantes sobre politicas de regularización en América latina. Santiago de Chile: CEPAL. Serie Medio Ambiente y Desarrollo, (75).

Elías, N. (2003). Ensayo acerca de las relaciones entre establecidos y forasteros. Revista Española de Investigación Sociológica REIS, 104, 219-251.

Guber, R. (2013). La articulación etnográfica. Descubrimiento y trabajo de campo en la investigación etnográfica de Ester Hermitte. Buenos Aires: Biblos.

Lefebvre, H. (2013). La producción del espacio. Madrid: Capitan Swing.

Lefebvre, H. (1978). De lo rural a lo urbano. Las relaciones entre el campo y la ciudad a la luz critica de la filosofía y la socio-

\section{territarias 34}

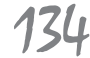

Lefebvre, H. (1976). Espacio y politica. El derecho a la ciudad II. Barcelona: Editorial Península.

Lefebvre, H. (1972). La revolución urbana. Madrid: Editorial Alianza.

Lefebvre, H. (1971). El materialismo dialéctico. Buenos Aires: La Pléyade.

Marx, K. (1998). El Dieciocho Brumario de Luis Bonaparte. Buenos Aires: Editorial Libertador.

Marx, K. (1968). Critica de la filosofía del Estado de Hegel. México: Grijalbo.

Marx, K. (1965). El Capital. Contribución a la crítica de la economía política. Buenos Aires: Editorial Cartago. Tomo I.

Marx, K., \& Engels, F. (1968). La ideología alemana. Uruguay: Ediciones Pueblos Unidos.

Muleras, E. (2008). Sacralización y desencantamiento. Las formas primarias del conocimiento del orden social. Buenos Aires: Miño y Dávila.

Núñez, A. (2004). ¿Cómo el Ave Fénix? Sobre la relación entre políticas urbanas y prácticas sociales. En B. Cuenya, C. Fidel \& H. Herzer (Orgs.) Fragmentos sociales: problemas urbanos en Argentina (pp. 235-250). Buenos Aires: Siglo XXI.

Núñez, A. (Dir.). (2007). Campo político, campo barrial... ¿ (Di) visiones en pugna? Mar del Plata: Ed. Suárez.

Núñez, A. (2008). Hay una cosa que se llama Mar del Plata, donde vive Martín... Sobre la génesis urbana y las fracciones sociales. Nómadas. Revista crítica de ciencias socialesy jurídicas, 17, 241-256.

Núñez, A. (2009). Abrir la política... urbana. Ni empresarios, ni burócratas, ni veci- 
nos: estatalidad profunda y estatalidad extensa. Economía, Sociedad y Territorio, $30(\mathrm{x}), 297-347$

Núñez, A. (2010). Tras el fetichismo de la vivienda digna. En P. Peyloubet, De Salvo \& L. Ortecho (Comps.), Ciencia y Tecnología para el Hábitat Popular. Fortalecimiento del espacio disciplinar en los Sistemas Cientifico Tecnológicos (pp. 201-218). Buenos Aires: Ed. Nobuko.

Núñez, A. (201la). Formas socioterritoriales de apropiación del habitar y derecho al espacio diferencial. Territorios 24,165192.

Núñez, A. (2011b). Las moradas del olvido... como tragedia. En A. Núñez \& A. Ciuffolini (Comps.). Politica y territorialidad en tres ciudades argentinas (pp. 37-60). Buenos Aires: El Colectivo ediciones.

Núñez, A. (2011c). Las moradas del olvido... como farsa. En En A. Núñez \& A. Ciuffolini (Comps.). Politica y territorialidad en tres ciudades argentinas (pp. 141-166). Buenos Aires: El Colectivo ediciones.

Núñez, A. (2012a). Lo que el agua (no) se llevó... Política urbana: poder, violencia e identidades sociales. Buenos Aires: ElColectivo ediciones. Colección Orlando Fals Borda.

Núñez, A. (2012b). Miserias de la propiedad. Apropiación del espacio, familia y clase social. Mar del Plata: eudem.

Núñez, A. (2013a). Indicadores de una vivienda adecuada en la interpretación Núñezizada del Pacto desc. Evaluación del programa de viviendas ix-Dignidad, en Mar del Plata (1998-2011). Arquisur, $4,160-177$.

Núñez, A. (2013b). Reflexiones sobre la estructura del valor del suelo. Incidentes en la psicogénesis del conocimiento en el caso Mar del Plata. Cuaderno urbano. Espacio, sociedad, cultura, 14(14), 51-69.

Piaget, J. y García, R. (1984). Psicogénesis $e$ historia de la ciencia. México: Siglo XXI. $2^{\mathrm{a}}$ ed.

Weffort, F. (1978). Apresentação. Em Moises, J. Contradições urbanas e movimentos sociais. $2^{\mathrm{a}}$ Ed. Rio de Janeiro: CEDEC/Paz e Terra. 
